\title{
Do realismo ao pós-realismo
}

\author{
Karl Erik Schøllhammer*
}

\begin{abstract}
Resumo
Quando falamos de realismo em relação à literatura brasileira contemporânea, acontece normalmente na chave da continuação do projeto histórico do romance do século 19 ou da perspectiva de um projeto representativo incompleto que ainda merece respeito e atenção pela tarefa de visualizar a realidade marginalizada, excluída e periférica da sociedade brasileira, principalmente nas grande cidades. Em ambos os casos entendese o realismo como um projeto representativo fortemente motivado pela consciência política e ética das injustiças excludentes de uma sociedade autoritária que amarra a literatura brasileira ao realismo. Hoje, olhando para a produção contemporânea não é difícil identificar os exemplos dessa continuidade e dessa retomada na reformulação do romance histórico em seus diferentes formatos. Para tratar dessa continuidade, observa-se aqui como o conceito de realismo traz, etimologicamente, uma ambiguidade paradoxal entre o realismo filosófico, que antes do Renascimento identificava uma realidade universal por trás das aparências sensíveis dos fenômenos, e o realismo na história da arte, que identifica as possibilidades miméticas no registro da semelhança criada pela via das representações. A mesma tensão opera hoje na discussão contemporânea do realismo, não na forma de um universalismo platônico, mas na emergência de uma metafísica em que o pensamento põe a estabilidade material à prova, numa espécie de atomismo da matéria que caracteriza o estético e onde o corpo do sujeito é engajado por uma vibração molecular indeterminada, uma sensação insensível desse nível de percepção e afeição sem sujeito que opera virtualmente na obra.

Palavras-chave: Realismo. Literatura Brasileira. Literatura contemporânea.
\end{abstract}

Quando falamos de realismo em relação à literatura brasileira contemporânea, acontece normalmente, na chave da continuação do projeto histórico do romance do século 19, a perspectiva de um projeto representativo incompleto que ainda merece respeito e atenção pela tarefa de visualizar a realidade marginalizada, excluída e periférica da sociedade brasileira, principalmente nas grandes cidades. Em ambos os casos entende-se o realismo como um projeto representativo fortemente motivado pela consciência política e ética das injustiças excludentes

* Pontifícia Universidade Católica do Rio de Janeiro (PUC-Rio) Professor associado e Diretor do Departamento de Letras da PUC-Rio. Pesquisador com bolsa de produtividade do CNPq. Cientista do Nosso Estado da Faperj (2007-2009/2013-2016). 
de uma sociedade autoritária que amarra a literatura brasileira ao realismo. Nas décadas de 1950 e 1960, as narrativas de nossos vizinhos latino-americanos enveredavam por caminhos do fantástico e do realismo mágico, e a literatura brasileira reformulava o realismo social do romance de 30 à prosa urbana da década de 1960. Mesmo durante certo fervor libertário do experimentalismo metadiscursivo do pós-moderno, da década de 1980, o realismo sempre foi a referência principal.

Hoje, olhando para a produção contemporânea, não é difícil identificar os exemplos dessa continuidade e dessa retomada na reformulação do romance histórico em seus diferentes formatos, como, por exemplo, no romance proletário de Luiz Ruffato - Inferno provisório -, no romance de formação de Paulo Scott - Habitante irreal -, ou na literatura que se debruça de modo etnográfico, documental ou testemunhal sobre a violência e a miséria social das grandes cidades - como em Cidade de Deus, de Paulo Lins, ou em Capão capado, de Ferréz. Sem sair do contexto desta discussão, o conceito de realismo se ampliou nas últimas décadas ao considerar com mais atenção a dimensão estética, isto é, os efeitos e afetos deixados pela representação. Assim, foi possível considerar efeitos de realismo que acompanhavam a representação literária e visual sem necessariamente estar em contraste com elas; uma inspiração inicial forte nesta abertura do conceito de realismo para aspectos de vivência da representação que se confundem com a experiência real. Roland Barthes foi um dos teóricos mais influentes, com os ensaios seminais "O efeito de real", de 1968, e posteriormente na interpretação desse detalhe insignificante à luz da dicotomia (BARTHES, 2012) entre studium e punctum, em que o punctum se refere ao impacto háptico e afetivo que desestabiliza as interpretações automáticas e ideológicas do sentido comunicado. Para a leitura de Barthes, a influência dos ensaios de Jacques Lacan (1984) sobre o "real" foi muito importante, e a concepção de uma vivência impossível no limite do "simbólico" sobreviveu e foi reformulada pelo historiador da arte Hal Foster (2014), no livro O retorno do real, como um efeito estético do trauma, um realismo traumático paradoxal que de maneira convincente oferecia um enquadramento teórico dos choques do real de uma cultura midiática pós-moderna. Para Foster, o realismo traumático concilia os dois paradigmas predominantes do século 20: o paradigma referencial, segundo o qual a imagem se refere a uma realidade fora de si; e o paradigma simulacral, em que uma imagem se refere apenas a uma outra imagem. A partir do exemplo da série Death in America, de 
Andy Warhol, Foster (2014) argumenta que a representação (impossível) do trauma criava efeitos de um real fortemente subversivo para a estabilidade simbólica do que se reconhece como realidade. Dessa perspectiva, a imagem torna-se um índice ou arquivo dessa mesma impossibilidade e insinua uma referencialidade superior acessível apenas em seus restos. Entretanto, não era só pela via da ruptura e do estranhamento que os efeitos emocionais e cognitivos da representação eram pensados; a dimensão afetiva no encontro entre a materialidade textual e o corpo do leitor ou do espectador se abriu como outro campo de exploração que, de certa maneira, evocava uma ontologia metafísica moderna naquilo que Rancière (1999) denominou a "sensação insensível”, que aparece em certo atomismo estético nas descrições representativas do romance realista e que, para o filósofo francês, evidencia o vínculo entre o realismo como movimento histórico e a emergência do regime estético. Procurei antes definir o impacto dessas singularidades afirmativas sobre as intersubjetividades afetivas como um realismo afetivo, em que a obra ganha realidade envolvendo o sujeito sensivelmente num desdobrar dinâmico de sua atualização no mundo.

Vale a pena observar aqui como o conceito de realismo traz, etimologicamente, uma ambiguidade paradoxal entre o realismo filosófico, que antes do Renascimento identificava uma realidade universal por trás das aparências sensíveis dos fenômenos, e o realismo na história da arte, que identifica as possibilidades miméticas no registro da semelhança criada pela via das representações. A mesma tensão opera hoje na discussão contemporânea do realismo, não na forma de um universalismo platônico, salvo talvez o caso da inestética de Alain Badiou, mas na emergência de uma metafísica em que o pensamento põe a estabilidade material à prova, numa espécie de atomismo da matéria que caracteriza o estético e onde o corpo do sujeito é engajado por uma vibração molecular indeterminada, uma sensação insensível desse nível de percepção e afeição sem sujeito que opera virtualmente na obra.

É importante reconhecer a relação íntima, no contexto do realismo, entre a representação visual e a letrada, cuja origem encontramos nos textos programáticos do perspectivismo renascentista, fortemente influenciados pela retórica clássica e depois pela maneira como o próprio conceito de realismo surge para caracterizar, de modo positivo, a pintura de Gustave Courbet (BROOKS, 2005). A metáfora visual é frequente nos textos programáticos do realismo histórico para idealizar certa transparência linguística na descrição realista, que se confundiria com 
o automatismo na aceitação da equivalência entre a percepção espontânea e a descrição dos cenários realistas. É sabido que a relação entre narrativa e descrição é um dos pontos cruciais nos debates em torno do realismo desde o ensaio "Narrar ou descrever", de Lukács (1965). Recentemente, o teórico literário Fredric Jameson retoma o dualismo entre narrar e descrever para fazer distinção entre o impulso de narrar e o afeto, que ele vincula diretamente à descrição. $O$ realismo se dá nessa relação de antinomia entre o impulso de narrar e o afeto, que ameaça o progresso da narrativa pela absorção sensível e derivativa. Nesse contraste dinâmico, Jameson consegue mostrar a cumplicidade entre o projeto realista do romance dos anos 1800 e o experimentalismo modernista que brota da materialidade linguística de uma autonomia descritiva que já se registra nas obras de Zola e Flaubert e a partir da qual se abre espaço para o experimentalismo poético da vanguarda. Não se aprofunda aqui a discussão da continuidade do realismo histórico; pretende-se, antes, interrogar outra tendência na narrativa brasileira, que parece falar de uma realidade bem concreta e reconhecível do cotidiano da classe média brasileira. Surgiu na literatura contemporânea uma voz frequentemente em primeira pessoa e que se expressa com uma coloquialidade simples e corriqueira, distante do trabalho experimental com as fronteiras expressivas da linguagem. Uma voz que expressa a própria experiência numa oralidade clara, que chega com facilidade aos ouvidos do leitor. Ao mesmo tempo, pode narrar uma história cujo desenvolvimento resulta fragmentário ou elíptico, com vácuos e ausências descritivos. A simplicidade direta do testemunho da própria condição é tensionada, assim, pela estrutura narrativa complexa, que desequilibra e intriga a compreensão.

Com alguma frequência, a fala direta é mediada pelo manuscrito, a carta ou o diário, e desse modo se retoma a autorreferencialidade, um dos traços mais característicos da literatura moderna. Por meio de uma escrita que cita outra escrita, refletia-se sobre a natureza do literário, num movimento de dobra em que seu processo e sua experiência se tornavam centro e objeto da escrita. Essa literatura metaficcional frisava sua consciência cética a respeito das ilusões possíveis de referencialidade objetiva, e o literário adquiriu sua autonomia nessa distância das funções comunicativas e representativas da linguagem.

O novo romance de Flávio Izhaki - Tentativas de capturar o ar (2016) convida a participar de um enredo filológico cuja narrativa se constrói numa investigação quase policial da genealogia do próprio romance. Em outras palavras, o manuscrito e sua história constituem o tema principal e confundem-se com o 
romance escrito por Izhaki. O livro abre com dois prefácios que explicitam o percurso derivado posteriormente do projeto inicial de escrita biográfica. Alexandre Pereira, principal autor das anotações apresentadas, pesquisou a vida de um escritor já falecido, Antônio Rascal, que depois de escrever três romances relevantes para a literatura brasileira cessou de publicar. Pereira trabalha na biografia do enigmático escritor até sofrer um acidente de carro fatal. As anotações sortidas que deixa são fragmentos de um processo de busca que, editados e acompanhados de prefácios e um posfácio de autoria alheia, se confundem com o livro que temos em mãos. Emerge daí a história de um manuscrito apócrifo que, resgatado e apresentado de forma fragmentária, com variedade de estilos e diversas autorias, oferece um mosaico elíptico e complexo da história biográfica a ser reconstruída. Confundemse a história da vida de Rascal e a relação do biógrafo com o próprio pai, biografia com autobiografia, priorizando o relato da investigação, guiado pelo enigma do silêncio precoce do escritor e pelas hipóteses sobre o que o teria motivado a parar de publicar. A inclusão de inéditos de Rascal determina o rumo da pesquisa de Pereira, pois entre eles há uma confissão de homicídio cometido por Antônio Rascal quando atropela, por acidente, uma pessoa e, em vez de socorrer a vítima, joga o corpo no rio. Esta revelação aparentemente chocante intriga o biógrafo, que encontra aí um motivo possível para o silêncio do escritor. Por outro lado, Pereira não consegue determinar a veracidade do fato e não chega a saber com certeza se se trata de confissão ou de ficção em primeira pessoa. Para a viúva e para o editor, não há dúvida sobre o caráter ficcional dos escritos de Rascal, mas para o biógrafo há neles o índice de um fato que poderia elucidar os rumos da vida do biografado.

Entre os escritores contemporâneos, Flávio Izhaki ganhou reconhecimento ainda em 2013, ao publicar seu segundo romance, Amanhã não tem ninguém, que se destacou entre os melhores do ano ao tornar-se semifinalista do prêmio Portugal Telecom de 2014. Nele se narrava a história de uma família pequenoburguesa carioca de origem judaica, numa construção narrativa complexa e com grande variedade de pontos de vista sobre os acontecimentos cotidianos de personagens de várias gerações. Em Tentativas de capturar o ar, também se destaca a habilidade na construção de uma estrutura narrativa elíptica e fragmentada, conduzida numa linguagem direta e coloquial em primeira pessoa, sem entraves à compreensão nem experimentos sintáticos próprios do trabalho linguístico da escrita modernista. Podemos assim observar como se concilia legibilidade discursiva com complexidade elíptica e incompletude fragmentária da estrutura. Trata-se talvez 
da característica de uma geração pós-realista em que se conciliam as demandas de transparência representativa e o ceticismo modernista e pós-moderno em relação ao projeto do realismo histórico. Por um lado, temos um discurso oral, centrado na primeira pessoa, que expressa uma realidade cotidiana de classe média facilmente identificável em suas características socioculturais; e, por outro, um discurso que se fundamenta sobre um mundo textualizado em que já não existem ilusões referenciais e no qual a representação sempre se dirige a outra representação, criando um jogo sedutor de semelhanças e analogias. Temos, portanto, um realismo que não se apoia na representação descritiva e sua fidelidade em relação ao mundo, nem no projeto subversivo da relação que caracterizava a literatura metaficcional, em que a denúncia apontava a falta de consistência ontológica do mundo em detrimento da força real da ficção. Na literatura pós-realista, que a meu ver caracteriza uma parte significativa da ficção contemporânea, observa-se uma inocência coloquial da enunciação íntima, que na estrutura narrativa desafia as fronteiras do domínio textual. No caso do romance de Izhaki, a indiscernibilidade entre confissão e ficção evoca a fatalidade de um evento que escapa à narração. A introdução do autobiográfico e das memórias íntimas, trazidos pela tendência autoficcional da literatura recente, é um dos recursos deste realismo particular, que só escapa do textualismo na medida em que consegue evidenciar uma vida maior e diferente do texto. No romance anterior de Izhaki, o tema subjacente era a fragilidade diante da doença; neste, é a emergência da realidade do crime e de sua confissão que marca a fronteira do ficcional. É a revelação de uma realidade fora do domínio textual que caracteriza a literatura pós-realista, certa resistência ética diante da ironia cética com relação ao construtivismo representativo daquilo que é considerado real. Sem demolir o espaço textual por via de estratégias retóricas, o pós-realismo reconhece a necessidade de certas respostas pragmáticas aos jogos desconstrutivos do sentido interpretativo. Os recursos são encontrados frequentemente em memórias pessoais, na autobiografia e em certa construção formativa do percurso do devir do personagem principal. $\mathrm{O}$ reconhecimento de detalhes raros cujo sentido se deixa narrativizar, mas que interferem no caminho do sujeito, é um dos traços que caracterizam essa procura de padrões, analogias e semelhanças mais fortes que as construções discursivas. Quando o narrador ou o personagem adquire a competência de entender os sinais e os índices da vida, diferentes e mais fortes que o texto, evoca-se a estrutura do romance de formação, na procura da capacidade de fazer sentido escrevendo a experiência desses limites, destacados pelos índices de uma potência objetiva que intervém na vida. 


\title{
From realism to post-realism
}

\begin{abstract}
In contemporary Brazilian literature, realism may be seen either as a sequence of the nineteenth-century historical project of the novel or as an incomplete representative project, that still deserves respect and attention for the task of portraying the marginalized, excluded, and peripheral realities of Brazilian society, mainly in large cities. In both cases, realism may be understood as a representative project, strongly motivated by the political and ethical awareness of the exclusionary injustices in an authoritarian society that ties Brazilian literature to realism. As we analyze Brazil's contemporary literary production, it is not difficult to pinpoint examples of how the nineteenth-century tradition of sequencing has been rescued and has reshaped the historical novel in its different formats. In order to deal with such continuity, it is observed here how the concept of realism brings, etymologically speaking, a paradoxical ambiguity: on the one hand, there is philosophical realism, which before the Renaissance identified a universal reality behind the sensible appearances of phenomena; on the other hand, there is realism in Art history, which identifies mimetic possibilities in the register of similarities, as they are generated by representations. The same tension operates now in the contemporary discussion of realism. Not in the form of Platonic universalism, but in the emergence of a kind of metaphysics in which thoughts put material stability to the test; as a sort of atomism of the aesthetic matter, in which the subject's body is engaged by indeterminate molecular vibrations - a callous sensation of perception and affection levels, deprived of a subject who operates virtually in the literary work.
\end{abstract}

Keywords: Realism. Brazilian literature. Contemporary literature.

\section{Referências}

BADIOU, Alain. Pequeno manual de inestética. Tradução de Marina Appenzeller. São Paulo: Estação Liberdade, 2002.

BARTHES, Roland. L'Effet du réel. Communications, n.11, p. 84-89, Paris: Éditions du Seuil, 1968.

BARTHES, Roland. A câmara clara: nota sobre a fotografia. Tradução de Júlio Castañon Guimarães. Edição especial. Rio de Janeiro: Nova Fronteira, 2012.

BROOKS, Peter. Realist Vision. New Haven / Londres: Yale University Press, 2005.

FERRÉZ. Capão Pecado. São Paulo: Planeta, 2013. 
FOSTER, HAL. O retorno do real. Tradução de Célia Euvaldo. São Paulo: Cosac Naify, 2014.

GUMBRECHT, Hans Ulrich. Atmosphere, Mood, Stimmung: On a Hidden Potential of Literature. Palo Alto: Stanford University Press, 2012.

IZHAKI, Flávio. Tentativas de capturar o ar. Rio de Janeiro: Rocco, 2016.

IZHAKI, Flávio. Amanhã não tem ninguém. Rio de Janeiro: Rocco, 2013.

JAMESON, Fredric. The antinomies of realism. Londres: Verso, 2013.

LACAN, Jacques. Do olhar como objeto 'a' minúsculo. In: LACAN, Jacques. O seminário, livro 11: Os quatro conceitos fundamentais da psicanálise. Tradução de M. D. Magno. Rio de Janeiro: Zahar, 1984.

LINS, Paulo. Cidade de Deus. São Paulo: Planeta, 2012.

LUKÁCS, Georg. Narrar ou descrever. Ensaios sobre a literatura. Tradução de Gisela Vianna Konder. Rio de janeiro: Civilização Brasileira. 1965. p. 43-94.

LYOTARD, Jean-François. L'Inhumain: causeries sur le temps. Paris: Galilée, 1988.

RANCIÈRE, J. Deleuze e a literatura. Matraga, Rio de Janeiro, n. 12, 2. sem., 1999.

RUFFATO, Luís. Inferno provisório. São Paulo: Companhia das Letras, 2016.

SCHØLLHAMMER, Karl Erik. Os novos realismos na arte e na cultura contemporânea. In: PEREIRA, Miguel; GOMES, Renato Cordeiro; FIGUEIREDO, Vera Lúcia Follain de. Comunicação, representação e práticas sociais. Rio de Janeiro: EdPuc, 2005.

SCOTT, Paulo. Habitante irreal. Rio de Janeiro, Objetiva, 2011.

Recebido em 09/09/2016

Aceito em 23/09/ 2016 